\title{
Emotion
}

\section{Pursuing Happiness in Everyday Life: The Characteristics and Behaviors of Online Happiness Seekers}

Acacia C. Parks, Matthew D. Della Porta, Russell S. Pierce, Ran Zilca, and Sonja Lyubomirsky Online First Publication, May 28, 2012. doi: 10.1037/a0028587

CITATION

Parks, A. C., Della Porta, M. D., Pierce, R. S., Zilca, R., \& Lyubomirsky, S. (2012, May 28).

Pursuing Happiness in Everyday Life: The Characteristics and Behaviors of Online Happiness

Seekers. Emotion. Advance online publication. doi: 10.1037/a0028587 


\title{
Pursuing Happiness in Everyday Life: The Characteristics and Behaviors of Online Happiness Seekers
}

\author{
Acacia C. Parks \\ Reed College
}

Ran Zilca

Signal Patterns, White Plains, New York

\author{
Matthew D. Della Porta and Russell S. Pierce \\ University of California, Riverside
}

Sonja Lyubomirsky

University of California, Riverside

\begin{abstract}
Although the last decade has witnessed mounting research on the development and evaluation of positive interventions, investigators still know little about the target population of such interventions: happiness seekers. The present research asked three questions about happiness seekers: (1) What are their general characteristics?, (2) What do they purposefully do to become happier?, and (3) How do they make use of self-help resources? In Study 1, we identified two distinct clusters of online happiness seekers. In Study 2, we asked happiness seekers to report on their use of 14 types of happiness-seeking behaviors. In Study 3, we tracked happiness seekers' usage of an iPhone application that offered access to eight different happiness-increasing activities, and assessed their resulting happiness and mood improvements. Together, these studies provide a preliminary portrait of happiness seekers' characteristics and naturalistic behaviors.
\end{abstract}

Keywords: happiness, intervention, positive psychology, smartphone, internet

Attaining long-term happiness is an important goal shared by many individuals world-wide (Diener, 2000; Diener, Suh, Smith, \& Shao, 1995; Goldberg et al., 2009). Trumping more "objective" factors like material wealth or physical attractiveness, happiness is central to lay people's beliefs about what makes life worth living (King \& Napa, 2008). However, happiness is more than just a personally important goal or a set of pleasant mood states; a meta-analysis of 225 cross-sectional, longitudinal, and experimental studies found that happiness is related to, precedes, and causes a variety of favorable life outcomes (Lyubomirsky, King, \& Diener, 2005). Among other desirable benefits, both long-term and short-term positive affect is directly associated with superior job outcomes (e.g., Lucas \& Diener, 2003), relatively more satisfying social relationships (e.g., Harker \& Keltner, 2001), and fewer symptoms of psychopathology (e.g., Diener \& Seligman, 2002).

Acacia C. Parks, Department of Psychology, Reed College; Matthew D. Della Porta and Russell S. Pierce, Department of Psychology, University of California, Riverside; Ran Zilca, Signal Patterns, White Plains, NY; Sonja Lyubomirsky, Department of Psychology, University of California, Riverside.

Acacia C. Parks is now in the Department of Psychology at Hiram College.

This research was supported in part by grants from the University of Pennsylvania's Positive Psychology Center and the University of California, Riverside's Academic Senate.

Correspondence concerning this article should be addressed to Acacia C. Parks, Department of Psychology, Hiram College, P.O. Box 67, Hiram, OH 44234. E-mail: parksac@ hiram.edu; or to Sonja Lyubomirsky, Department of Psychology, University of California, Riverside, CA 92521. Email: sonja.lyubomirsky@ucr.edu
Not surprisingly, happiness-oriented self-help constitutes one of the most consistently lucrative markets for popular books. Unfortunately, however, the self-help genre is flooded with "pop psychology" that lack scientific grounding. Furthermore, recent work by Mauss and colleagues (2011) suggests that increasing happiness may be more complicated than it sounds, as valuing happiness too strongly can undermine one's ability to pursue it successfully (Mauss, Tamir, Anderson, \& Savino, 2011). However, a growing number of studies conducted over the last decade have demonstrated the efficacy of techniques that target well-being (for a review and a meta-analysis, see Parks \& Biswas-Diener (in press); Sin \& Lyubomirsky, 2009). For example, randomized controlled interventions have prompted people to write gratitude letters, savor happy memories, and do acts of kindness on a regular basis. A recent meta-analysis conducted by Sin and Lyubomirsky (2009) reported that such techniques lead to increases in happiness and small to moderate decreases in depressive symptoms (average effect size $r \mathrm{~s}=.29$ and .31 , respectively). In short, researchers are well on their way to creating a science of increasing happiness.

However, despite a substantial body of literature on the efficacy of happiness-increasing exercises, remarkably little discussion has focused on exactly for whom these exercises are intended. Furthermore, researchers know very little about what members of their target audience (i.e., "happiness seekers") are doing on their own, prior to their becoming participants in research. A variety of descriptive questions remain unanswered by standard intervention research designs: When individuals seek to become happier, what are their starting points in terms of baseline happiness and distress? How much effort do happiness seekers expend on the pursuit of happiness in the absence of formalized instruction? How do happiness seekers balance the use of multiple exercises to increase 
their happiness, and how many activities do happiness seekers practice simultaneously? Last, whereas many activities that target well-being have been shown to lead to sustained improvements in laboratory or online settings, researchers have yet to offer persuasive evidence that happiness activities, as they are actually used in real-world settings, are beneficial.

The goal of the present research is to address each of these questions in turn, with the aim of gaining an improved understanding of who happiness seekers are and what they are doing in the real world. In Study 1, we assessed the demographic and psychological characteristics of a sample of happiness seekers. In addition to examining aggregate data, we used cluster analysis to test the hypothesis that the sample is not homogenous, but, rather, that different subsets of happiness seekers may exist. In Study 2, we asked happiness seekers about the extent to which they used 14 categories of happiness-increasing activities. We were particularly interested in the extent to which naturalistic use of happiness exercises mirrored the ways in which these exercises are used in experimental studies.

In Study 3, we collected naturalistic data on happiness seekers' usage of an iPhone application that offered access to eight different activities found to increase happiness in previous research. We also examined the extent to which certain patterns of usagefrequency of use both across and within individuals, and variety of activities practiced-led to increased self-reported happiness among users. Together, these three studies provide a preliminary portrait of the happiness seekers: Who they are, what they do when left to their own devices, how they utilize happiness-increasing tools in naturalistic settings, and how much they benefit from engaging in positive activities in the "real world." It is our hope that these data will serve as the foundation for a new body of work describing this population.

\section{Study 1}

The purpose of Study 1 was to provide a preliminary descriptive portrait of happiness seekers as a group. By drawing from a sample of individuals with an explicit interest in engaging in happinessincreasing behaviors, we can paint a picture of the attributes characteristic of this population-a population that, until now, has been largely hypothetical in the literature. Specifically, we sought to clarify two aspects of happiness seekers.

First, whereas the populations targeted by interventionists in the field of clinical psychology (e.g., those with depression or anxiety) are clearly defined and relatively easy to identify, positive intervention researchers know very little about the demographic characteristics of happiness seekers. Furthermore, whereas clinical intervention researchers place a high priority on testing interventions on the population for whom they are intended, the bulk of positive intervention research has been conducted not with happiness seekers but with undergraduates or other general population samples. This practice assumes, perhaps falsely, that the average happiness seeker is, like the average person, somewhat happy and relatively free of depressive symptoms (Pavot \& Diener, 1993; Radloff, 1977).

In addition, the majority of positive intervention studies examine both sample characteristics and intervention efficacy at an aggregate level. This approach assumes that happiness seekers are homogeneous, and that responses to positive interventions will be similar for individuals along the entire continuum of baseline distress. However, little evidence supports either of these assumptions. Across most (if not all) mental health conditions, moderators such as personality and baseline symptom levels predict responses to different treatments; for example, individuals with mild-tomoderate depression do not benefit as much from medication as individuals with more severe depression (Fournier et al., 2010). The same may be true for happiness seekers. For example, a recent study of healthy undergraduates found that those who were initially mildly depressed benefited the most from a positive intervention (Layous \& Lyubomirsky, 2011). In sum, while investigators are busy attempting to determine which exercises are most globally effective for the average person, they may be overlooking the existence of different subtypes of happiness-seeking individuals, each with distinct goals, motivations, and responsiveness to interventions.

Study 1 addressed the two above concerns by first reporting on the demographic and psychological characteristics of happiness seekers, and then attempting to cluster happiness seekers into subtypes based on those characteristics. We had two objectives: (1) to report the characteristics of a sample of happiness seekers and (2) to explore whether there exist distinct "subgroups" of happiness seekers.

\section{Method}

\section{Participants}

Participants were 912 self-help seeking adults ranging in age from 21 to $83(M=45.51, S D=12.43)$. The sample was primarily female $(77 \%)$ and largely Caucasian (87\%), with $4.4 \%$ of participants characterizing themselves as Asian or Asian American, 2.1\% Black or African American, 2.0\% Hispanic or Latino(a) American, $0.3 \%$ Native American, and $4.2 \%$ mixed or unspecified ethnicity. The majority of the sample was based in the United States, but $42 \%$ reported living outside the United States. It was an educated sample $(91.3 \%$ had completed at least some college, and $69.9 \%$ had a bachelor's degree or more), but income was evenly distributed across six income blocks, which ranged from "under \$20K" to "over \$99K."

\section{Procedure}

The data used in this study were drawn from a larger dataset, the collection of which took place on a rolling basis ${ }^{1}$ beginning in July 2006 and ending in February 2007. Each potential participant arrived at the study website (http://www.ppresearch.sas .upenn.edu) via one of two ways: (1) a link from authentichappiness.org, a website run by the University of Pennsylvania's Positive Psychology Center that exists primarily to make a variety of well-being self-assessments available to the general public, or (2) by browsing the web (e.g., searching for the phrase "participate in positive psychology research"). The larger study invited participants to complete a randomly assigned happiness-increasing exercise for a week; thus, all participants were Internet users interested

\footnotetext{
1 Participants could enter the study at any point during this 7-month
} period. 
in becoming happier. Interested participants completed a webbased registration and consent process then filled out a battery of questionnaires that included demographic questions, as well as various psychological measures that had been included in the larger study as outcome measures (see below). Analyses were performed on data from this single measurement occasion.

\section{Assessments $^{2}$}

Depressive symptoms were measured using the Center for Epidemiological Studies Depression Scale (CES-D; Radloff, 1977), a 20-item public-domain depression measure. For each item (e.g., "I felt sad"), the respondent provides a rating ranging from 0 (Rarely or none of the time, $<1$ day) to 3 (Most or all of the time, 5-7 days). Three counterbalanced items are reverse scored, and then scores are totaled to provide an overall rating of depressive symptom severity that ranges from 0 to 60 , with 16 as a standard cutoff for clinical severity levels (Radloff, 1977). The average CES-D score in the general population is between 8 and 9, with between $15 \%$ and $19 \%$ scoring above the cutoff (Radloff, 1977).

Life Satisfaction was measured with the five-item Satisfaction With Life Scale (SWLS; Diener, Emmons, Larson, \& Griffin, 1985. Using a scale of 1 (strongly disagree) to 7 (strongly agree), with a neutral middle point $(4=$ neither agree nor disagree $)$, participants rate their satisfaction with the conditions of their life (e.g., "In most ways my life is close to my ideal") and their satisfaction with their life choices (e.g., "If I could live my life over, I would change almost nothing"). Their ratings are then totaled, to provide a score ranging from 5 (low satisfaction) to 35 (high satisfaction). The average SWLS score in the general population ranges from 23 to 28 , between "slightly satisfied" and "satisfied" (Pavot \& Diener, 1993).

General happiness levels were assessed using the Authentic Happiness Inventory (Seligman, Steen, Park \& Peterson, 2005; AHI), a 24-item scale that asks participants to rate on a five-point scale $(-1=$ negative, $0=$ neutral, $1=$ somewhat positive, $2=$ very positive, and $3=$ extremely positive) their agreement with a series of statements that address three aspects of happinesspleasure, engagement, and meaning.

The Positive and Negative Affect Scale (PANAS; Watson, Clark, \& Tellegen, 1988) includes 20 emotions-10 positive and 10 negative. Participants rate their current experience of each emotion on a scale of 1 to 5. The positive items are totaled into a positive affect (PA) subscore, and the negative items are totaled into a negative affect (NA) subscore. These two subscores can be examined either separately or as an "affect balance" score (i.e., PA - NA or PA/NA). In the present study, we were interested especially in the extent to which individuals' affect balance ratios approached or exceeded the lower cutoff of 2.9:1 previously found for "flourishing" individuals, as reported by Fredrickson and Losada (2005). A quantification of the balance of positive and negative emotions complements the CES-D, which examines negative states in isolation, as well as the two well-being scales we included (AHI and SWLS), which examine positive states in isolation. Combined, these measures provide a more complete picture of each participant's emotional state.

\section{Results and Discussion}

\section{Sample Characteristics}

On average, participants in this sample of happiness seekers reported depressive symptom levels slightly above the CES-D clinical cutoff of $16(M=17.44, S D=12.72)$ and well above the mean of the general population (see above). Mean life satisfaction was in the "neutral" range $(M=20.56, S D=8.20)$, also below the average for the general population. Mean happiness scores on the AHI were between "neutral" and "somewhat positive" $(M=0.87$, $S D=0.71$ ), and the mean affect balance ratio was 2.15:1 (positive to negative emotions), which is significantly lower than the 2.9:1 cutoff for "flourishing." $t(911)=-20.82, p<.0001$.

\section{Cluster Analysis}

We performed a series of two-step cluster analyses (Everitt, Landau, \& Leese, 2001) to evaluate the potential existence of subgroups within the larger sample of happiness seekers. An initial model containing all demographic and well-being variables was a poor fit for the data. The final model, which provided the optimal fit, included only the four continuous mood variables: depressive symptoms, life satisfaction, affect balance, and general happiness. The resulting analysis produced a two-cluster model.

The first cluster (which, for descriptive purposes, we will call the "nondistressed" cluster) represented $50.5 \%$ of the sample and was characterized by average depressive symptom scores $(M=$ 7.93, $S D=5.85)$, average levels of life satisfaction $(M=26.89$, $S D=4.83$ ), and an affect balance (positive to negative) ratio of 2.91:1 $(S D=0.85)$, which is just above the 2.9:1 cutoff for flourishing. The average AHI score was 0.87 on a scale of -1 to $3(S D=0.71)$, between the "somewhat positive" and "very positive" range.

The second cluster (for descriptive purposes, the "distressed" cluster), which comprised the remaining $49.5 \%$ of the sample, reported levels of depressive symptoms well above the clinical cutoff of $16(M=26.74, S D=10.58)$, below average life satisfaction $(M=14.36, S D=5.69$; as described above, the population average is 23 to 28 ), and an affect balance ratio of $1.41: 1(S D=.71)$. The average AHI score was $0.32(S D=0.47)$, or "neutral."

\section{Differences Between the Clusters}

Recall that participants rated themselves as having one of the following: (1) no history of depression, (2) a past history of depression but no current depression, or (3) current depression. Individuals reporting current depression were almost 6 times more likely to belong to the "distressed" cluster ( $41 \%$ of the sample) than to the "nondistressed" cluster (7\% of the sample). Similarly, a significantly larger number of individuals reporting a clean bill of mental health, with no past history of depression, were in the "nondistressed" cluster (60\%), as compared with the "distressed"

\footnotetext{
2 All measures used in Study 1 have previously-reported alphas of .8 or higher. Because of the design of the web-based system, which calculated total scores automatically and loaded them directly into the dataset, we were unable to calculate alphas for this sample.
} 
cluster (27\%). Among participants who did report a past history of depression, however, cluster membership was not predictive, $\chi^{2}(3$, $n=912)=160.50, p<.0001 .^{3}$

In short, the "distressed" cluster was not only generally more distressed than the "nondistressed" cluster-its members were also significantly more likely to suffer from depression. The clusters did not differ on other demographic variables (all $p s>.05$ ).

\section{Summary and Implications}

The cluster structure that emerged in this sample revealed that roughly half of happiness seekers are exactly who researchers would expect-namely, individuals who are not exceptionally happy, but who are not suffering from clinical depression either. However, our results also suggest the existence of another substantial subset of happiness seekers who are very distressed, possibly even suffering from a mental health condition. Whereas the 12-month prevalence of depression in the general population is estimated to be $6.7 \%$ (Kessler et al., 2005), this sample of happiness seekers showed much higher rates of current depression (according to self-reports).

At the very least, this finding is worthy of attention from anyone who designs, studies, or applies positive interventions in practice. The possibility that individuals with heightened depressive symptoms are seeking positive interventions which have yet to be shown to be effective for distressed individuals (see Seligman et al., 2006, for a rare exception) should give researchers pause. ${ }^{4}$ Although some evidence suggests that happiness activities may be most effective for those individuals who are the least happy (see Layous \& Lyubomirsky, 2011; Sin \& Lyubomirsky, 2009), we do not know whether this finding would apply to the clinically significant distress reported by individuals in the "distressed" cluster.

\section{Limitations}

As with any theory derived from data, the cluster model supported in this study must be replicated in multiple samples. Although the present sample likely approximates happiness seekers more accurately than those provided by previous research, by no means is it a representative sample of all happiness seekers, or even of all happiness seekers on the Internet. The sample contained individuals from across the globe and with a wide range of incomes, but participants were also largely white, educated, and female. It is unclear to what extent these features of the sample were the result of sampling bias, and to what extent they may be informative about the composition of happiness seekers as a group. In other words, it may be that happiness seekers are largely female, white, and educated, but further research is necessary to determine whether this is the case.

In addition, although we considered a wide variety of demographic and psychological variables when creating our model, other variables that were not included could further inform our classification of happiness seekers. For example, we included neither measures of individual differences (i.e., the Big 5 personality traits) that may serve as indices of person-activity fit, nor measures of other positive psychological variables such as physical health, gratitude, optimism, curiosity, and mindfulness. Furthermore, future research would do well to assess the extent to which an individual's subtype has practical significance-for ex- ample, whether it impacts his or her response to a given positive exercise.

Although Study 1 began to paint a picture of the characteristics of happiness seekers, it left open many questions about this population's behavioral attributes, as well as the extent to which happiness seekers are successful in their practice of happinessincreasing exercises in naturalistic settings. These questions were addressed in Studies 2 and 3, respectively.

\section{Study 2}

The purpose of Study 2 was to examine the ways that individuals use happiness-increasing activities in their everyday lives. Study designs for happiness interventions are, as a rule, highly controlled, with the intent of maximizing internal validity - that is, establishing that happiness strategies cause increases in happiness (Cook \& Campbell, 1979). However, several aspects of the traditional experimental design used by positive intervention researchers-each of which we outline below-may undermine ecological validity, or the ability to demonstrate a relationship between happiness-boosting strategies and increased subjective well-being observed in a real-world context.

First, experimental studies typically assign participants to practice one particular happiness strategy at a time (vs. a comparison control activity) throughout the study. In the real world, however, people may practice a variety of happiness activities within a short period. For example, after coming home from work, a person may decide to call a friend to congratulate him, go for a bike ride, write in a gratitude journal, and spend an hour learning how to play guitar, all in a single night. Studying a single happiness strategy at a time may not reflect the multifaceted nature by which people attempt to increase their well-being. By asking happiness seekers precisely what they are doing to become happier in their everyday lives, we can examine their natural behavior patterns and assess the extent to which the single-exercise research design is an appropriate way to investigate the pursuit of happiness.

Second, typical experimental procedures in randomized controlled positive interventions dictate when, for how long, and how frequently the participant must engage in a particular happiness activity over the course of a predetermined number of days or weeks (Sin \& Lyubomirsky, 2009). Whereas experiments generally set a standardized frequency with which participants practice

\footnotetext{
3 Whereas this finding may seem puzzling at first, this pattern is consistent with research on the course of depression, which suggests that some individuals experience full remission with infrequent relapse, while other experience depression as more chronic, with residual symptoms between episodes (American Psychiatric Association, 2000). Although we have no way of confirming or denying this in our data, we speculate that members of the "non-distressed" cluster who had prior depression tended to have experienced the former course of depression, while members of the "distressed" cluster tended to have experienced the latter. Thus, because members of both clusters end up falling under the "history of depression" category (for different reasons), this variable does not predict group membership.

4 It is possible that a similar cluster structure would emerge in a control group of individuals seeking other types of self-help (for example, cognitive bibliotherapy); however, this would be less troubling, as cognitive bibliotherapy has been tested in clinically depressed populations, whereas happiness-oriented self-help has not.
} 
an exercise, in reality, there are many different frequencies and durations with which an individual may practice an exercise, and evidence suggests that some approaches are better than others. For example, one study found that participants who performed five acts of kindness on a single day each week increased in selfreported happiness, but those who performed five acts of kindness throughout the week did not (Lyubomirsky, Sheldon, et al., 2005). The majority of studies, however, do not examine dosage variations.

Furthermore, in the real world, people practice happinessboosting activities according to their own preferences. Rather than following a regimented protocol, they may modify the activity in ways that they believe will maximize its efficacy for them. It may be that each individual has a unique set of specifications (e.g., variety of positive activities practiced, whether those activities are practiced as instructed, or modified), matched to his or her preferences and personality (cf. Lyubomirsky, 2008; Schueller, 2010). Thus, it is critical to determine the ways in which individuals do and do not customize happiness activities when practicing them in daily life.

Finally, a great deal of evidence shows that people tend to adapt to the emotional impact of positive and negative stimuli over time (Frederick \& Lowenstein, 1999; Lyubomirsky, 2011). Research on positive events and activities, such as getting married (Lucas \& Clark, 2006) or earning a promotion (Boswell, Boudreau, \& Tichy, 2005), suggests a general pattern of hedonic adaptation, such that people experience a boost in happiness at the start of the positive change, followed by an eventual return to their original baseline level of happiness as they grow accustomed to the change and begin to take it for granted. It is possible, then, that just as individuals adapt to changes in their life circumstances, they may also adapt to any initial happiness boosts they might obtain from engaging in a self-improvement program. However, many positive intervention studies to date are silent on the issue of hedonic adaptation. As a result, researchers generally do not know whether individuals hedonically adapt to the activities they perform, and if so, how long it takes for that adaptation to occur. It is also unknown if and how individuals adjust their behavior-perhaps by varying the practice or timing of the strategy, or by engaging in the strategy in novel or surprising ways - to inhibit hedonic adaptation (Lyubomirsky, 2011). The data collected in this exploratory study allow us to examine how happiness seekers manage the problem of adaptation, which may, in turn, inform experimentalists' efforts to address the adaptation problem in their research designs.

In our second study, we used cross-sectional data collected online from a sample of happiness seekers to ask several questions that we would be unable to assess using more traditional intervention designs. Specifically, we examined the naturalistic behaviors of happiness seekers with the goal of evaluating the ecological validity of the experimental designs typically used to study happiness interventions.

\section{Method}

\section{Participants}

Participants ( $n=114 ; 89$ female, 25 male) were recruited through online advertisements inviting people to share what they do to make themselves happier. The online advertisements ap- peared on classified ad sites (e.g., http://www.craigslist.org), as well as on websites that host ongoing lists of psychology research studies looking for participants (e.g., http://psych.hanover.edu/ research/exponent.html). Thus, most of the participants who selfselected themselves into the study were those already practicing real-world happiness strategies. However, some may have been engaged in preexisting behaviors meant for purposes other than becoming happier. The mean age was $26.19^{5}(S D=10.96)$, and the sample was $73.7 \%$ Caucasian, $9.6 \%$ Hispanic, $4.4 \%$ Asian American, 4.4\% African American, 2.6\% American Indian, and $0.9 \%$ Hawaiian. Three and a half percent indicated "more than one ethnicity," and $0.9 \%$ indicated "other." No compensation was offered for participation.

Of 160 original participants, 46 individuals who did not list any activities that made them happy were excluded from analyses because our critical measures were dependent on participants listing at least one activity that they practice.

\section{Procedure}

The online survey was conducted as part of a single session and took approximately 25 minutes to complete. When participants logged into the study website, they completed an online consent form. After agreeing to participate in the study, they were asked to provide demographic information such as gender, ethnicity, and age before proceeding to the main survey, which comprised three sections.

First, participants were asked to list up to 10 happiness strategies that they currently practice. Then, they were presented with a checklist of 14 categories of happiness strategies. This checklist was based on the framework of happiness-increasing activities described in Lyubomirsky (2008) (see Table 1). Participants were asked to "select any activity category below that describes a positive activity that [they] currently practice."

Second, participants were asked to identify one activity from the previously generated list that was most important or most meaningful to them. They then rated the frequency with which they used that activity $(1=$ once every several months, $2=$ once a month, $3=$ a few times a month, $4=$ once a week, $5=$ several times $a$ week, $6=$ every day, $7=$ more than once a day), as well as the duration of the average episode/session in which they used the specified activity $(1=$ less than a minute, $2=1-10$ minutes, $3=$ 10-20 minutes, $4=20-40$ minutes, $5=40-60$ minutes, $6=1-2$ hours, 7 = more than 2 hours).

Finally, participants were asked to identify one happiness activity to which they had hedonically adapted from the original list that they had generated. Adaptation was defined as follows: "Adaptation' or 'habituation' happens when people no longer benefit as much from practicing a happiness strategy as they did when they

\footnotetext{
5 It is worth noting that although both Study 1 and Study 2 samples consist of Internet users, the Study 2 sample is substantially younger, on average, than the sample in Study 1. Recruitment methods for each study may have drawn a different subset of Internet users.
} 
Table 1

Most Commonly Practiced Activities, Activities to Which Participants Adapted, and the Most Important/Meaningful Activities (Study 2)

\begin{tabular}{|c|c|c|c|}
\hline Happiness-increasing activity & $\begin{array}{l}\% \text { Participants practicing } \\
\text { this activity }^{\mathrm{a}}\end{array}$ & $\begin{array}{l}\% \text { Participants identifying this } \\
\text { activity category as one to } \\
\text { which they most adapted }\end{array}$ & $\begin{array}{l}\% \text { Participants identifying this } \\
\text { activity category as most } \\
\text { important or meaningful }^{\text {b }}\end{array}$ \\
\hline Practicing acts of kindness towards others & 77.2 & 2.6 & 5.3 \\
\hline Pursuing goals that are important to me & 73.7 & 6.1 & 5.3 \\
\hline Expressing gratitude & 68.4 & 0 & 0 \\
\hline Being optimistic & 68.4 & 0 & 0 \\
\hline Doing physical exercise or sports & 65.8 & 14.9 & 11.4 \\
\hline Nurturing my social relationships & 62.3 & 16.7 & 52.6 \\
\hline Savoring life's joys & 61.4 & 21.9 & 4.4 \\
\hline Acting like a happy person & 60.5 & 0 & 0 \\
\hline \multicolumn{4}{|l|}{ Doing activities that make me feel "in the } \\
\hline moment" & 59.6 & 15.8 & 4.4 \\
\hline Forgiving others & 58.8 & 0 & 0 \\
\hline Practicing religion and/or spirituality & 41.2 & 2.6 & 7.9 \\
\hline \multicolumn{4}{|l|}{ Using strategies that help me cope with } \\
\hline stress or adversity & 40.4 & 16.7 & 3.5 \\
\hline \multicolumn{4}{|l|}{ Avoiding overthinking and comparing } \\
\hline myself to others & 37.7 & 0 & 0 \\
\hline Practicing meditation & 20.2 & 0.9 & 1.8 \\
\hline None of the categories fit & & 1.8 & 3.5 \\
\hline
\end{tabular}

${ }^{a}$ More than one category could be selected. ${ }^{\mathrm{b}}$ As determined by coders.

first started."6 Two coders independently determined to which activity category this activity best corresponded (see Table 1). If coders disagreed, one of the researchers (second author) made a final judgment.

After participants identified one activity to which they had adapted, they were asked to rate the extent of the adaptation to using that activity ("To what degree have you adapted/habituated to practicing your happiness strategy, such that you no longer get the same feeling of happiness or satisfaction from it as you did in the beginning?") on a seven-point scale (1 = very slightly or not at all, $4=$ somewhat, $7=$ extremely). They were also asked to report on the timeline of their adaptation ("How long after you started practicing this happiness strategy did you start to adapt/ habituate (i.e., when did the boost in happiness or other benefits you initially obtained start to diminish)?") on an eight-point scale $(0=$ I never habituated, $1=$ less than one day, $2=$ a few days, 3 = one week, $4=$ several weeks, $5=$ one month, $6=$ several months, $7=$ more than six months). Last, they were asked to report on their reaction to the onset of adaptation (i.e., "Once you started to adapt/habituate to this positive activity, such that you no longer got the same feeling of happiness or satisfaction from it as you did in the beginning, what did you decide to do?") by selecting one of the following options: (1) I kept practicing the activity in the same way, even though I wasn't benefiting as much from it; (2) I tried to practice the same activity in a new way; (3) I tried a new activity; (4) I stopped practicing; (5) I don't know; and (6) Other).

\section{Results and Discussion}

\section{Number and Types of Activities Practiced}

Each of the 14 categories of activities was endorsed by at least $20 \%$ of participants, suggesting that all 14 categories represent authentic activities practiced by happiness seekers. When asked to generate lists of up to 10 real-world happiness strategies that they were currently practicing, as well as to match the activities they use in daily life with the 14 possible categories, participants produced an average of 7.75 activities $(S D=2.80)$ and selected an average of 7.96 categories $(S D=3.47)$.

The percentage of participants who selected each individual activity category is shown in Table 1 . The majority of activities were endorsed by more than half of participants (58.6\% to $77.2 \%$ ), with the most popular activities being practicing acts of kindness (77.2\%) and pursuing goals (73.7\%). Four activities were endorsed somewhat less frequently than the others: practicing religion and/or spirituality (41.2\%), using strategies to cope with stress or adversity (40.4\%), avoiding overthinking and social comparison (37.7\%), and practicing meditation (20.2\%).

\section{Most Valued Activity}

When asked which of the 14 activity categories was most important or meaningful to them, about half of participants (52.6\%) chose "nurturing my social relationships." The other half of participants' endorsements was spread out among the remaining activities. Only $3.5 \%$ of participants reported that their most valued activity was not represented by the list we gave them, suggesting that the list provides a reasonable representation of the activities that matter to happiness seekers. Our participants reported practicing their most important or meaningful activity, on average, between "several times a week" and "every day" $(M=$

\footnotetext{
${ }^{6}$ Although participants may report no longer benefiting from practicing an activity because they did not implement it correctly or implemented it in an inappropriate context, we believe this possibility unlikely, because in that case they would have not obtained an initial happiness boost from the activity.
} 
$5.57, S D=1.32$ ). The practice duration for this activity was reported to be between "40-60 minutes," and "1-2 hours," on average $(M=5.67, S D=1.62)$.

\section{Experiences of and Reactions to Adaptation}

Participants reported having adapted to five activities more so than the others: Doing physical exercise (14.9\%), nurturing social relationships $(16.7 \%)$, savoring life's joys $(21.9 \%)$, feeling "in the moment" (15.8\%), and coping with stress or adversity (16.7\%). When asked to think about an activity to which they had adapted, participants, on average, reported having "somewhat" adapted to its effects $(M=4.03, S D=1.53)$. Adaptation typically occurred "several months" after participants began practicing their happiness strategy $(M=6.16, S D=2.22)$. When asked to report what they did when adaptation first became evident, the most common responses were as follows: "I did the same activity in a new way" $(28.1 \%)$, "I kept practicing the same activity the same way" (26.3\%), "I don't know" (14.9\%), "I tried a new activity" (12.3\%), "Other" (9.6\%), and "I stopped practicing the activity" (8.8\%).

\section{Summary and Implications}

These findings reveal several important characteristics of happiness strategies, as they are practiced in the real world, which contrast sharply with those of happiness strategies administered in experimental settings.

First, whereas participants reported using an average of between seven and eight activities, the majority of positive interventions require participants to attempt only one activity (e.g., Sheldon \& Lyubomirsky, 2006), or, if practicing a series of activities, practicing one activity per week and working through the various activities over the course of several weeks (e.g., Seligman, Rashid, \& Parks, 2006). Using multiple positive activities simultaneously is likely to inhibit adaptation to their hedonic benefits (Lyubomirsky, 2011) by bolstering variety and novelty, rendering the activities more effective for longer periods of time. The finding that happiness seekers voluntarily choose to practice up to eight happiness strategies at a time suggests that by experience or instinct they have discovered a successful approach to the pursuit of happiness. Experimental research, then, may be requiring participants to practice activities in ways that are both artificial and potentially conducive to adaptation.

Second, whereas many intervention studies report follow-up assessments between one and three months postintervention (e.g., Emmons \& McCullough, 2003, Study 1), participants reported that adaptation did not occur, on average, until "several months" after beginning to practice the activity. This finding highlights the need for follow-ups that extend 6 months, or even 9 or more months, postintervention.

Third, participants reported, on average, practicing their most important or meaningful activity more than several times a week for at least an hour each time. Notably, most experimental interventions have sought to minimize the time commitment required of participants, asking participants to practice an assigned activity once per week (e.g., Lyubomirsky, Sheldon, et al., 2005) or, if on a daily basis, for only a few minutes each day (e.g., Emmons \& McCullough, 2003, Study 2). These instructions appear to under- shoot both the frequency and the duration of practice that is desired by participants.

In short, our results from Study 2 lend credibility to the proposition that traditional happiness intervention research designs are not representative of the ways in which happiness-increasing activities are used in the real world. Furthermore, these data offer novel information regarding the day-to-day practices of happiness seekers. As noted above, little is known about the people for whom happiness-boosting exercises are intended. However, they also provide concrete suggestions for ways in which research designs can be improved to create a more ecologically valid setting for testing happiness interventions.

\section{Limitations}

Although the Study 2 data reveal several important characteristics of happiness strategies as they are used in the real world, our design has limitations. First, participants were required to make retrospective judgments, which may be based on imperfect and biased memories. To be sure, previous research has shown that individuals' retrospective reports are distorted by a variety of factors, including momentary mood (Schwarz \& Clore, 1983) and expectations (Mitchell, Thompson, Peterson, \& Cronk, 1997). Hence, a participant may report that she did not start adapting to a particular happiness-enhancing strategy until after several months of practice, whereas real-time tracking of that activity may yield evidence of adaptation beginning much earlier.

Perhaps most important, our correlational survey data did not allow us to determine whether practicing happiness strategies in a real-world context was related to boosts in well-being, nor how our findings would compare to a control group of individuals not actively seeking happiness. Although studying what happiness strategies people choose to do in the real world (and how they choose to do them) is an important scientific endeavor, not knowing whether such strategies are effective mitigates the importance of the findings. Also, it is unclear whether nonhappiness seekers would have reported similar responses, thus making it impossible to determine whether these data elucidate the real-world practices of those trying to become happier. Fortunately, our third study, which explored the practice of real-world happiness strategies via a novel technology, was able to able to address some of the limitations of Study 2 by assessing improvements in mood and happiness via real-time measurements.

\section{Study 3}

The purpose of Study 3 was to gather further evidence about how happiness activities are practiced in the context of people's daily lives. Although a growing number of studies show that happiness strategies are effective in an experimental setting (Sin \& Lyubomirsky, 2009), it remains unclear whether performing these activities is related to boosts in well-being in the real-world. To investigate these questions, researchers need a way to capture authentic experience.

Experience sampling methodology (ESM) is one naturalistic study method that provides a way to investigate real-world behavior. This technique typically requires participants to provide responses during their everyday lives either after being signaled by a beeper device or after performing a particular activity (Conner, 
Tennen, Fleeson, \& Barrett, 2009). Previous research has shown that ESM can reveal information that would not have been obtained using retrospective, self-report data, more accurately capturing peoples' behavioral, affective, and cognitive experiences (Conner et al., 2009; Kurtz \& Lyubomirsky, in press). However, the increased precision of assessment is associated with a cost; ESM is often both burdensome and invasive for participants, disrupting their daily lives and possibly interrupting the ways in which they might ordinarily carry out happiness-increasing strategies.

For these reasons, researchers are beginning to develop ways of collecting data via devices already integrated into participants' lives-most notably, smartphones. Recent data show that the most popular smartphone, the iPhone, has sold approximately $42,487,000$ units to date, including $8,400,000$ in the first quarter of 2010 (Apple Incorporated, 2010). In addition, consumers have downloaded more than 5 billion iPhone applications (Sarno, 2010). These statistics suggest that the use of smartphones and smartphone applications are prevalent. Such devices have the unique advantage of being able to provide a platform for applications that are designed specifically to collect data or record behavior for a particular study (Kurtz \& Lyubomirsky, in press). Thus, rather than disrupting the use of happiness strategies, smartphone software can be used as a tool for the optimal completion of happinessincreasing exercises.

By using an iPhone application called Live Happy, we were able to use a methodology in this study that was a unique extension of ESM. This application gave participants the opportunity to practice eight different happiness strategies according to their own preferences and schedules. In contrast to prior research, in which participants are rewarded or reimbursed for engaging in the activities under study, our participants purchased and used the Live Happy application without being prompted. This potentially makes Study 3 participants the most representative of the three samples reported in this paper. If it is the goal of researchers developing happiness interventions to reach happiness seekers, many of whom purchase self-help materials, then researchers should be interested in participants who will pay to become happier. Although the necessarily self-selected time points that result from this type of assessment are limited by lack of experimenter control (e.g., application users may choose not to supply before and after happiness reports), by definition, they reflect participants' naturalistic experience.

Following previous experimental studies on happinessincreasing activities (e.g., Sin \& Lyubomirsky, 2009), we expected that engaging in the positive activities included in the Live Happy application would be associated with increases in mood and happiness. In particular, we expected that greater usage would result in greater benefit. Furthermore, we hypothesized that engaging in a greater variety of activities - in line with the naturalistic behavior observed in Study 2-would result in larger increases in wellbeing.

\section{Method}

\section{Participants}

Activity performance was assessed in 2,928 participants who purchased Live Happy from Apple's online application store and demonstrated active use of the application by using at least one of the happiness promoting activities more than once. Participants used the application-which contained the activities, as well as two mood assessments - freely, and so mood data were only available for the subset of participants who chose both to use the activities and complete the mood questionnaires. Mood changes were assessed in 327 participants who took mood assessment questionnaires on at least two occasions that were 3 to 14 days $\operatorname{apart}^{7}(M=8.74$ days, $S D=2.70$ days $)$ and had baseline scores under the maximum of 7.0, to allow room for growth.

\section{Procedure}

Participants purchased the \$0.99 Live Happy application for the iPhone and freely completed the activities or mood and happiness measures on their own time. The application offers eight exercises: (1) savoring the moment, (2) remembering happy days, (3) acts of kindness journal, (4) strengthening social relationships, (5) goal evaluation and tracking, (6) gratitude journal, (7) expressing gratitude personally, and (8) thinking optimistically. Each has been empirically found to be effective at enhancing positive states (see below).

The first two happiness-increasing exercises involved savoring positive experiences. In the "savoring the moment" exercise, users take a picture of something that is beautiful or meaningful and write a short paragraph describing what they appreciate and value in it (Schueller, 2010); and, in the "remembering happy days" exercise, users attempt to replay their emotions and feelings during a previous happy day and write them down (with an option to include a picture from the iPhone's photo album) (Lyubomirsky, Sousa, \& Dickerhoof, 2006).

The second set of activities include a journal for recording acts of kindness (for happiness-boosting effects, see Boehm, Lyubomirsky, \& Sheldon, in press; Dunn, Aknin, \& Noton, 2008; Lyubomirsky, Sheldon, et al., 2005; Otake, Shimai, TanakaMatsumi, Otsui, \& Fredrickson, 2006) and a "strengthening social relationships" exercise, which offers the option to contact a close other from the user's contacts and calling, emailing, or texting them to revive and strengthen the relationship with them (Gable, Reis, Asher, \& Impett, 2004). A fifth activity, labeled "Strive," involves a "goal evaluation and tracking" system (e.g., Sheldon \& Houser-Marko, 2001). In this activity, users list and evaluate goals to ensure they are attainable and begin initial steps toward achieving them.

Two gratitude-related activities constituted a "Gratitude Journal" exercise in which users write down one thing for which they are grateful in each journal entry (for well-being benefits, see Emmons \& McCullough, 2003; Froh, Sefick, \& Emmons, 2008; Lyubomirsky, Sheldon, et al., 2005) and an "expressing gratitude personally" exercise in which they can choose a person they wish to thank from their contacts to email, call, or text (see Lyubomirsky, Dickerhoof, Boehm, \& Sheldon, 2011; Lyubomirsky, Sheldon, et al., 2005; Seligman et al., 2005). Finally, the last intervention, "Optimism," involves a "thinking optimistically" exercise,

\footnotetext{
7 The 3- to 14-day interval was an arbitrary cutoff assigned by the researchers at the outset of the study, before data were collected or analyzed; we estimated that fewer than 3 days would be insufficient time for benefits to occur, but that greater than 14 days between assessments would introduce extraneous noise.
} 
which prompts users to think about their best possible future scenario and write about it (for well-being benefits, see Burton \& King, 2008; Lyubomirsky et al., 2011; Sheldon \& Lyubomirsky, 2006).

\section{Assessments}

Our mood measure (L. R. Goldberg, Renfrow, \& Zilca, 2011), reflecting the affective component of happiness, comprised six items similar to the ones included in Barrett and Russell's (1998) Revised Positive and Negative Affect Scale. Participants were asked to report "How [they] feel right now" using colored sevenpoint scales, in which red represents the negative extreme, yellow represents the positive extreme, and shades of red and yellow represent the middle points. The six items, which were averaged together to create a single mood index score, were sad/happy, timid/confident, ashamed/unashamed, gloomy/cheerful, irritable/ good-natured, and afraid/unafraid $(\alpha=.86)$. In previous research (L. R. Goldberg et al., 2011), this measure has correlated highly with the PA $(r=.63)$ and NA $(r=-.67)$ subscales of the PANAS (Watson, Clark \& Tellegen, 1988).

Subjective happiness was assessed with three items. The first two items were drawn from the Subjective Happiness Scale (Lyubomirsky \& Lepper, 1999). The first item, "In general, I consider myself a very happy person," was assessed using a seven-point scale, with colors ranging from red $(1=n o)$ to yellow $(7=y e s)$, instead of numbers. The second item, "Compared to most of my peers, I consider myself ...," was color coded in the same way, with ratings taking place on a scale of 1 (less happy) to 7 (more happy). The third item was adapted from the SWLS (Diener et al., 1985). This item, "In general, I consider myself satisfied with my life," was assessed using the same color coded 1-to-7 scale. The three items were averaged together to create a single happiness index score.

\section{Results and Discussion}

\section{Popularity of Exercises}

Popularity was assessed among the subset of participants who used one or more of the activities on the Live Happy application more than once. Table 2 lists the number of participants using the application for whom a given activity was the one they performed most often. If particular participants had multiple activities that

Table 2

Participants' Most Frequently Performed Activities (Study 3)

\begin{tabular}{lc}
\hline Happiness-increasing activity & $\begin{array}{c}\text { Number of participants } \\
\text { who practiced this } \\
\text { activity the most }\end{array}$ \\
\hline Goal evaluation and tracking & 897 \\
Savoring the moment & 639 \\
Gratitude journal & 498 \\
Thinking optimistically & 363 \\
Remembering happy days & 255 \\
Strengthening social relationships & 109 \\
Expressing gratitude personally & 90 \\
Acts of kindness journal & 79 \\
\hline
\end{tabular}

they performed an equal number of times, the value representing their preference was split evenly among those activities. Each of the eight exercises was the most frequently used activity for some percentage of participants (in other words, no exercise was nobody's favorite), although substantial variation was observed in their popularity. "Goal evaluation and tracking," for example, was by far the most popular activity, with $31 \%$ of users practicing it most frequently out of the eight exercises. Savoring was the most frequently used activity for $22 \%$ of users, and the gratitude journal was most frequently used for another $17 \%$. The "acts of kindness journal" and the "expressing gratitude personally" exercises, however, were favored by far fewer participants-2.7\% and $3.1 \%$, respectively. This contrasts with data from Study 2, which suggested that when participants are choosing activities freely, they often choose strategies that approximate the categories of "acts of kindness" and "expressing gratitude." Thus, it seems that happiness seekers may prefer to act differently, depending on whether their happiness-increasing activities arise naturally or are prompted by instructions from an outside source.

\section{Application Usage and Well-Being Benefits}

Participants' mood scores improved from the first $(M=4.46$, $S D=1.25)$ to the second $(M=4.87, S D=1.32)$ assessment, $t(782)=8.90, p<.001$, to an extent greater than would be expected by chance. Happiness scores also improved from the first $(M=4.14, S D=1.33)$ to the second $(M=4.48, S D=1.33)$ assessment, $t(326)=6.61, p<.001$. Adding time since initial assessment, the interaction between baseline scores and time, or both to the model, did not predict additional variance in mood, $F(2$, $779)=0.21, p=.81$, or in happiness, $F(2,323)=0.98, p=.38$, at follow up.

Increases in mood were predicted by the frequency with which the activities in the application were used, $b=.02, F(1,780)=$ $16.32, p<.001$, as were increases in happiness, $b=.01, F(1$, $324)=7.60, p=.006$. The number of different types of activities completed (see Table 3 ) also predicted increases in mood, $b=.06$, $F(1,780)=14.30, p<.001$, and happiness, $b=.05, F(1,324)=$ $5.42, p=.02$.

\section{Summary and Implications}

Previous experimental research has provided evidence for a causal relationship between happiness-promoting interventions and well-being. Study 3 corroborates this evidence by bolstering its ecological validity. By combining the methodological strengths of ESM (i.e., real-time and multiple time point measurement) with the noninvasive nature of smartphone data collection, our study design enabled participants to decide when to complete activities and complete subjective well-being assessments. This methodology allowed us to track real-world happiness strategies by assessing participants' preferences for engaging in particular activities, as well as the degree to which they actually reported becoming happier.

As expected, use of the Live Happy application was related to increases in well-being - namely, both mood and happiness scores improved between users' first and second assessments. Furthermore, the more often people used the Live Happy application (i.e., the higher total number of activities completed), and the greater the 
Table 3

Variety of Activities Engaged in by Participants (Study 3)

\begin{tabular}{cc}
\hline $\begin{array}{c}\text { Number of activities } \\
\text { engaged in }\end{array}$ & $\begin{array}{c}\text { Number of participants engaging } \\
\text { in that number of activities }\end{array}$ \\
\hline 1 & 433 \\
2 & 469 \\
3 & 532 \\
4 & 475 \\
5 & 358 \\
6 & 314 \\
8 & 196 \\
\hline
\end{tabular}

variety of activities they practiced, the greater the increases they reported in their mood and happiness. These results provide preliminary evidence for the ecological validity of practicing happiness strategies - that is, strategies practiced according to the natural preferences of people as they live their lives were related to actual increases in well-being.

\section{Limitations}

The biggest limitations of Study 3 were that it lacked random assignment and a control group. This shortcoming, unfortunately, prevents us from making any causal statements regarding the efficacy of the application and makes it difficult to rule out the possibility that improvements experienced by users might have been due, at least in part, to regression to the mean effects. That is, assuming that people are more likely to pay for a happiness iPhone app at a time when they are particularly distressed, they are likely to witness a natural dissipation, or at least reduction, of that distress over time regardless of any outside intervention.

Although regression may seem a plausible explanation for our findings, differences in efficacy among the individual activities suggest otherwise; in rough terms, our relatively ineffective happiness activities can serve as a proxy control group. Any activities that outperform other activities, then, are more likely to represent practices that are genuinely effective in improving well-being. Nevertheless, future research would ideally use one or more placebo and comparison conditions (e.g., use of an alternate iPhone app that is equally engaging, but inert from a theoretical standpoint and/or a wait-list control) to bolster researchers' confidence in the sources of their self-help outcomes.

\section{General Discussion}

The goal of the current study was to provide a descriptive account of happiness seekers' characteristics and behaviors. In Study 1, we found that happiness seekers are a diverse group in terms of both demographic and psychological characteristics. Study 2 relied on retrospective self-reports to examine what activities people practice, how they practice them, and their experiences practicing them. Finally, Study 3 used a mobile application that allows users to practice happiness activities in their daily lives as a platform to assess which real-world happiness strategies are most popular and whether they are associated with boosts in well-being. Below, we highlight several noteworthy findings.

\section{Happiness Seekers Are Not Homogeneous}

Our cluster analysis revealed the existence of two distinct subsets of happiness seekers, suggesting that happiness seekers are not a homogeneous group. The one-size-fits-all approach to increasing happiness typically used by researchers may thus need to be supplanted by a more nuanced model that takes baseline symptom levels, among other factors, into consideration. These two clusters of individuals may have unique goals, preferences, and needs with respect to self-improvement. Further, baseline symptom levels may alter the effectiveness of a given activity. For example, more engagement-oriented activities could be problematic for individuals with depression, as engagement is characterized by deep engrossment in an intrinsically rewarding activity, and depression is characterized by difficulty concentrating and lack of enjoyment. Conversely, consistent with evidence that positive emotions can "undo" negative emotions (cf. Fredrickson, 2001, 2009), it may be that activities targeting positive emotion are ideal for depressed individuals. Indeed, preliminary evidence suggests substantial variation in individuals' responses to positive interventions; whereas certain activities may be especially beneficial for people with depression (Layous \& Lyubomirsky, 2011), others may be ineffective, or even harmful, for a particular subset of depressed participants (Sergeant \& Mongrain, 2011; Sin, Della Porta, \& Lyubomirsky, 2011).

Thus, distinguishing between "distressed" and "nondistressed" happiness seekers could serve as a useful criterion for determining person-activity fit. Membership in one of these clusters, for example, may establish who is likely to benefit from an activity, who will not get much out of the activity, and who is likely to find the activity too taxing, depressing, or otherwise harmful. Investigating other individual differences among users of happiness activities may similarly yield valuable information that can be applied in developing responsible recommendations to consumers.

\section{Happiness Strategies Work in the Real World, With Some Caveats}

Study 2 demonstrates that individuals in the real world use the types of happiness-increasing strategies that researchers are studying empirically, and Study 3 provides preliminary evidence consistent with the idea that these activities are effective when used in a naturalistic setting. Although these findings lend support to the idea that happiness interventions are helpful to people in the real world, they also call attention to some important caveats.

Participants may not know best. Participants' preferences for engaging in particular happiness-increasing strategies were not necessarily predictive of those strategies' effectiveness. Two very popular activities among users in our data- "goal evaluation and tracking" and "savoring the moment"-were not associated with increased happiness or mood, suggesting that participants may not have made optimal judgments regarding which activities might work best for them. Indeed, previous research indicates that people are typically poor predictors of how they will be impacted by future positive or negative events (see Wilson \& Gilbert, 2003, for a review).

One explanation for the noted discrepancies between the outcomes observed and the outcomes expected (by researchers and participants alike) is that particular happiness-increasing strategies 
may be more sensitive to precise conditions and specificationsand thus more subject to "degradation"- than others. Certain activities, then, may need to be performed by individuals exactly as instructed to insure their efficacy, whereas others activities may be customized to particular situations and individuals, without losing their efficacy to boost well-being. Such an explanation is plausible in the case of goals, as only certain types of goals are related to long-term increases in happiness (Sheldon et al., 2010). Thus, the participants in our sample may have chosen goals that are not conducive to well-being, reducing the activity's effectiveness. Given that at least $28 \%$ of our participants in Study 2 modified the activities they were using, the effect of adherence to instructions on efficacy for each of these activities warrants further investigation.

Another potential explanation for the disparity between preference and effectiveness is that our participants may have preferred activities that they have already tried and engaged in regularly. In this scenario, the participant may be benefiting from his most preferred activities as much as possible. Rather than using his preference for a given activity as a gauge that he should do that particular activity more often, the participant may be better off using the fact that he enjoys one activity to select other activities that are likely to work for him (see Schueller, 2010, for an example of how this might be accomplished).

Variety is the spice of self-improvement. The majority of positive intervention studies ask participants to use a single exercise. There are good reasons for this practice; if participants practice multiple activities in tandem, it is difficult to assess which behaviors are associated with psychological benefits. However, this scenario appears to be one that is rarely, if ever, observed in everyday practice; participants in Study 2 used eight activities on average and, although Study 3 participants could have chosen to focus their efforts on a single exercise out of the eight available, most did not.

Beyond being unrealistic, the single-exercise study design may undermine the performance of positive interventions. In Study 3, engaging in not only a greater number of activities, but in a greater variety of activities, was predictive of larger mood improvements. Thus, limiting participants to a single exercise is not only artificial, but may lead to an underestimation of that exercise's efficacy. This finding lends credence to the "buffet" approach proposed by Parks, Schueller, and Tasimi (2011) and operationalized by Seligman, Rashid, and Parks (2006) — if given a choice, individuals will "try on" a variety of exercises, then select a subset to continue practicing independently.

That happiness seekers naturally engage in a variety of activities, and that variety leads to greater mood improvements, has implications for the study of hedonic adaptation. It may be that "mixing it up" is a strategy that real-world happiness seekers use to keep activities from losing their impact; if so, further research can determine under what circumstances variety leads to better outcomes, and whether there is an optimal level of variety. Perhaps even more important, such research can continue to explore the mechanisms through which varied activity may protect against hedonic adaptation to the rewards of positive activities (for preliminary work, see Lyubomirsky, 2011; Sheldon, Boehm, \& Lyubomirsky, in press; Sheldon \& Lyubomirsky, in press).

\section{The Future of Positive Intervention Research: A Role for Technology}

Although experimental control lends obvious advantages when evaluating the efficacy of an intervention, happiness-increasing strategies must also be studied as they occur naturally in a realworld context and in the individuals for whom they are designed. Evidence supporting the ecological validity of happiness activities will supplement knowledge gained from experimental studies and provide a more complete understanding of the utility of these activities. The present studies were a first attempt to accomplish this goal.

Evidence elucidating the characteristics and benefits of realworld happiness strategies is important because it suggests that the same interventions used in controlled experimental settings can have benefits when performed in a relatively uncontrolled manner. Furthermore, the naturalistic study designs reported here can be useful as a model for future research, which could integrate traditional experimental designs with more externally valid assessment and intervention approaches.

Technology provides an exciting opportunity to close the gap between research and implementation. Because researchers have access to diverse populations using the Internet, testing interventions in the populations for whom they are intended is becoming more and more feasible. The use of smartphone technology adds an additional layer of realism, allowing researchers to create phone-based interfaces for interventions and then, as participants use these interfaces, track participants' behaviors and moods as they occur. In the future, researchers have much to gain from designing protocols that resemble the everyday practice of happiness strategies. Doing so will help to identify new experimental variables worthy of manipulation, as well as potentially bolster the ecological validity of their experimental designs.

Although both ESM and smartphone data collection have clear limitations, together they provide a high fidelity representation of people's bona fide experiences as they strive for greater happiness. The present studies suggest that real-world happiness strategies have observable unique characteristics and that it is indeed possible to begin to assess the benefits of such practices in real-time through the use of innovative technologies. As technology progresses, the ability to study real-world happiness strategies in new and methodologically diverse ways will advance accordingly. The use of smartphone applications to administer happiness strategies and collect data is just one way to improve on study designs formerly limited by technological restrictions.

\section{References}

American Psychiatric Association. (2000). Diagnostic and statistical manual of mental disorders (4th ed., text rev.). Washington, DC: Author.

Apple Incorporated. (2010). Unaudited condensed consolidated statements of operations. Retrieved from http://www.apple.com/pr/library/2010/07/ 20results.html

Barrett, L. F., \& Russell, J. A. (1998). Independence and bipolarity in the structure of current affect. Journal of Personality and Social Psychology, 74, 967-984. doi:10.1037/0022-3514.74.4.967

Boehm, J. K., Lyubomirsky, S., \& Sheldon, K. M. (in press). A longitudinal experimental study comparing the effectiveness of happinessenhancing strategies in Anglo Americans and Asian Americans. Cognition and Emotion. 
Boswell, W. R., Boudreau, J. W., \& Tichy, J. (2005). The relationship between employee job change and job satisfaction: The honeymoonhangover effect. Journal of Applied Psychology, 90, 882-892. doi: 10.1037/0021-9010.90.5.882

Burton, C. M., \& King, L. A. (2008). Effects of (very) brief writing on health: The two-minute miracle. British Journal of Health Psychology, 13, 9-14. doi:10.1348/135910707X250910

Conner, T. S., Tennen, H., Fleeson, W., \& Barrett, L. F. (2009). Experience sampling methods: A modern idiographic approach to personality. Social and Personality Psychology Compass, 3, 292-313. doi:10.1111/ j.1751-9004.2009.00170.x

Cook, T. D., \& Campbell, D. T. (1979). Quasi-experimentation. Boston, MA: Houghton Mifflin.

Diener, E., Emmons, R. A., Larsen, R. J., \& Griffin, S. (1985). The Satisfaction With Life Scale. Journal of Personality Assessment, 49, 71-75. doi:10.1207/s15327752jpa4901_13

Diener, E., \& Seligman, M. E. P. (2002). Very happy people. Psychological Science, 13, 81-84. doi:10.1111/1467-9280.00415

Diener, E., Suh, E. K., Smith, H., \& Shao, L. (1995). National differences in reported well-being: Why do they occur? Social Indicators Research, 34, 7-32. doi:10.1007/BF01078966

Diener, E. (2000). Subjective well-being: The science of happiness and a proposal for a national index. American Psychologist, 55, 34-43. doi: 10.1037/0003-066X.55.1.34

Dunn, E. W., Aknin, L. B., \& Norton, M. I. (2008). Spending money on others promotes happiness. Science, 319, 1687-1688. doi:10.1126/ science. 1150952

Emmons, R. A., \& McCullough, M. E. (2003). Counting blessings versus burdens: An experimental investigation of gratitude and subjective wellbeing in daily life. Journal of Personality and Social Psychology, 84, 377-389. doi:10.1037/0022-3514.84.2.377

Everitt, B., Landau, S. \& Leese, M. (2001). Cluster analysis. New York: Taylor \& Francis.

Fournier, J. C., DeRubeis, R. J., Hollon, S. D., Dimidjian, S., Amsterdam, J. D., Shelton, R. C., \& Fawcett, J. (2010). Antidepressant drug effects and depression severity. Journal of the American Medical Association, $303,47-53$.

Frederick, S., \& Loewenstein, G. (1999). Hedonic adaptation. In D. Kahneman, E. Diener, \& N. Schwarz (Eds.), Well-being: The foundations of hedonic psychology (pp. 302-329). New York: Russell Sage Foundation.

Fredrickson, B. L., \& Losada, M. F. (2005). Positive affect and the complex dynamics of human flourishing. American Psychologist, 60, 678-686. doi:10.1037/0003-066X.60.7.678

Fredrickson, B. L. (2001). The role of positive emotions in positive psychology: The broaden-and-build theory of positive emotions. American Psychologist, 56, 218-226. doi:10.1037/0003-066X.56.3.218

Fredrickson, B. L. (2009). Positivity. New York: Crown.

Froh, J. J., Sefick, W. J., \& Emmons, R. A. (2008). Counting blessings in early adolescents: An experimental study of gratitude and subjective well-being. Journal of School Psychology, 46, 213-233. doi:10.1016/ j.jsp.2007.03.005

Gable, S. L., Reis, H. T., Asher, E. R., \& Impett, E. A. (2004). What do you do when things go right? The intrapersonal and interpersonal benefits of sharing positive events. Journal of Personality and Social Psychology, 87, 228-245. doi:10.1037/0022-3514.87.2.228

Goldberg, A. B., Fillmore, N., Andrzejewski, D., Xu, Z., Gibson, B., \& Zhu, X. (2009). May all your wishes come true: A study of wishes and how to recognize them. In Human language technologies (pp. 263-271). Boulder, CO: Association for Computational Linguistics.

Goldberg, L. R., Rentfrow, J., \& Zilca, R. (2011). [A brief bipolar scale of affect.] Unpublished raw data.

Harker, L., \& Keltner, D. (2001). Expressions of positive emotions in women's college yearbook pictures and their relationship to personality and life outcomes across adulthood. Journal of Personality and Social Psychology, 80, 112-124. doi:10.1037/0022-3514.80.1.112

Kessler, R. C., Chiu, W. T., Demler, O., Merikangas, K. R., \& Walters, E. E. (2005). Prevalence, severity, and comorbidity of 12-month DSM-IV disorders in the National Comorbidity Survey Replication. Archives of General Psychiatry, 62, 617-627. doi:10.1001/archpsyc .62.6.617

King, L. A., \& Napa, C. K. (1998). What makes a life good? Journal of Personality and Social Psychology, 75, 156-165. doi:10.1037/00223514.75.1.156

Kurtz, J. L., \& Lyubomirsky, S. (in press). Positive psychology. In M. R. Mehl \& T. S. Conner (Eds.), Handbook of research methods for studying daily life. New York, NY: Guilford Press.

Layous, K., \& Lyubomirsky, S. (2011). Is variety the spice of a happiness intervention? Unpublished manuscript, Department of Psychology, University of California, Riverside.

Lucas, R. E., \& Clark, A. E. (2006). Do people really adapt to marriage? Journal of Happiness Studies, 7, 405-426. doi:10.1007/s10902-0069001-X

Lucas, R. E., \& Diener, E. (2003). The happy worker: Hypotheses about the role of positive affect in worker productivity. In M. Burrick \& A. M. Ryan (Eds.), Personality and work (pp. 30-59). San Francisco, CA: Jossey-Bass

Lyubomirsky, S., Dickerhoof, R., Boehm, J. K., \& Sheldon, K. M. (2011). Becoming happier takes both a will and a proper way: An experimental longitudinal intervention to boost well-being. Emotion, 11, 391-402. doi:10.1037/a0022575

Lyubomirsky, S., King, L., \& Diener, E. (2005). The benefits of frequent positive affect: Does happiness lead to success? Psychological Bulletin, 131, 803-855. doi:10.1037/0033-2909.131.6.803

Lyubomirsky, S., \& Lepper, H. S. (1999). A measure of subjective happiness: Preliminary reliability and construct validation. Social Indicators Research, 46, 137-155. doi:10.1023/A:1006824100041

Lyubomirsky, S., Sheldon, K. M., \& Schkade, D. (2005). Pursuing happiness: The architecture of sustainable change. Review of General Psychology, 9, 111-131. doi:10.1037/1089-2680.9.2.111

Lyubomirsky, S., Sousa, L., \& Dickerhoof, R. (2006). The costs and benefits of writing, talking, and thinking about life's triumphs and defeats. Journal of Personality and Social Psychology, 90, 692-708. doi:10.1037/0022-3514.90.4.692

Lyubomirsky, S. (2008). The how of happiness: A scientific approach to getting the life you want. New York, NY: Penguin Press.

Lyubomirsky, S. (2011). Hedonic adaptation to positive and negative experiences. In S. Folkman (Ed.), Oxford handbook of stress, health, and coping (pp. 200-224). New York, NY: Oxford University Press.

Mauss, I. B., Tamir, M., Anderson, C. L., \& Savino, N. (2011). Can seeking happiness make people unhappy? Paradoxical effects of valuing happiness. Emotion, 11, 807-815. doi:10.1037/a0024986

Mitchell, T. R., Thompson, L., Peterson, E., \& Cronk, R. (1997). Temporal adjustment of the evaluation of events: The "rosy view." Journal of Experimental Social Psychology, 33, 421-448. doi:10.1006/ jesp.1997.1333

Otake, K., Shimai, S., Tanaka-Matsumi, J., Otsui, K., \& Fredrickson, B. L. (2006). Happy people become happier through kindness: A counting kindnesses intervention. Journal of Happiness Studies, 7, 361-375. doi:10.1007/s10902-005-3650-z

Parks, A. C. \& Biswas-Diener, R. (in press). Positive interventions: Past, present and future. To appear in T. Kashdan \& Ciarrochi, J. (Eds.), Bridging Acceptance and Commitment Therapy and Positive Psychology: A Practitioner's Guide to a Unifying Framework. Oakland, CA: New Harbinger.

Parks, A. C., Schueller, S. \& Tasimi, A. (in press). Increasing happiness in the general population: Empirically Supported Self-Help? To appear in 
I. Boniwell \& S. David (Eds.), Oxford Handbook of Happiness. Oxford: Oxford University Press.

Pavot, W. \& Diener, E. (1993). Review of the satisfaction with life scale. Psychological Assessment, 5, 164-172.

Radloff, L. S. (1977). The CES-D Scale: A self-report depression scale for research in the general population. Applied Psychological Measurement, $1,385-401$

Sarno, D. (2010, June 7). Apple announces new iPhone 4: The Steve Jobs Keynote. The Los Angeles Times. Retrieved from http://www.latimes .com

Schueller, S. M. (2010). Preferences for positive psychology exercises. The Journal of Positive Psychology, 5, 192-203. doi:10.1080/ 17439761003790948

Schwarz, N., \& Clore, G. L. (1983). Mood, misattribution, and judgments of well-being: Informative and directive functions of affective states. Journal of Personality and Social Psychology, 45, 513-523. doi: 10.1037/0022-3514.45.3.513

Seligman, M. E. P., Rashid, T., \& Parks, A. C. (2006). Positive psychotherapy, American Psychologist, 61, 774-788. doi:10.1037/0003066X.61.8.774

Seligman, M. E. P., Steen, T. A., Park, N., \& Peterson, C. (2005). Positive psychology progress: Empirical validation of interventions. American Psychologist, 60, 410-421. doi:10.1037/0003-066X.60.5.410

Sergeant, S., \& Mongrain, M. (2011). Are positive psychology exercises helpful for people with depressive personality styles? The Journal of Positive Psychology, 6, 260-272. doi:10.1080/17439760.2011.577089

Sheldon, K. M., Abad, N., Ferguson, Y., Gunz, A., Houser-Marko, L., Nichols, C. P., \& Lyubomirsky, S. (2010). Persistent pursuit of needsatisfying goals leads to increased happiness: A 6-month experimental longitudinal study. Motivation and Emotion, 34, 39-48. doi:10.1007/ s11031-009-9153-1

Sheldon, K. M., Boehm, J. K., \& Lyubomirsky, S. (in press). Variety is the spice of happiness: The hedonic adaptation prevention (HAP) model. In
I. Boniwell \& S. David (Eds.), Oxford handbook of happiness. Oxford, UK: Oxford University Press.

Sheldon, K. M., \& Houser-Marko, L. (2001). Self-concordance, goalattainment, and the pursuit of happiness: Can there be an upward spiral? Journal of Personality and Social Psychology, 80, 152-165. doi: 10.1037/0022-3514.80.1.152

Sheldon, K. M., \& Lyubomirsky, S. (2006). How to increase and sustain positive emotion: The effects of expressing gratitude and visualizing best possible selves. The Journal of Positive Psychology, 1, 73-82. doi:10.1080/17439760500510676

Sheldon, K. M., \& Lyubomirsky, S. (in press). The challenge of staying happier: Testing the Hedonic Adaptation Prevention (HAP) model. Personality and Social Psychology Bulletin.

Sin, N. L., Della Porta, M. D., \& Lyubomirsky, S. (2011). Tailoring positive psychology interventions to treat depressed individuals. In S. I. Donaldson, M. Csikszentmihalyi, \& J. Nakamura (Eds.), Applied positive psychology: Improving everyday life, health, schools, work, and society (pp. 79-96). New York, NY: Routledge.

Sin, N. L., \& Lyubomirsky, S. (2009). Enhancing well-being and alleviating depressive symptoms with positive psychology interventions: A practice-friendly meta-analysis. Journal of Clinical Psychology, 65, 467-487. doi:10.1002/jclp.20593

Watson, D., Clark, L. A., \& Tellegen, A. (1988). Development and validation of brief measures of Positive and Negative Affect: The PANAS scales. Journal of Personality and Social Psychology, 54, 1063-1070.

Wilson, T. D., \& Gilbert, D. T. (2003). Affective forecasting. Advances in Experimental Social Psychology, 35, 345-411. doi:10.1016/S00652601(03)01006-2

Received June 15, 2011

Revision received December 30, 2011

Accepted January 9, 2012 